\title{
The PTEN pathway in Tregs functions as a critical driver of the immunosuppressive tumor microenvironment and tolerance to apoptotic cells
}

\author{
Madhav Sharma', Rahul Shinde ${ }^{1}$, Tracy McGaha', Lei Huang ${ }^{1}$, Rikke Holmgaard², Jedd Wolchok², Mario Mautino ${ }^{3}$, \\ Esteban Celis ${ }^{1}$, Arlene Sharpe ${ }^{4}$, Loise Francisco ${ }^{4}$, Jonathan Powell ${ }^{5}$, Hideo Yagita ${ }^{6}$, Andrew Mellor ${ }^{1}$, Bruce Blazar ${ }^{7}$, \\ David Munn ${ }^{8^{*}}$
}

From 30th Annual Meeting and Associated Programs of the Society for Immunotherapy of Cancer (SITC 2015)

National Harbor, MD, USA. 4-8 November 2015

The tumor microenvironment is profoundly immunosuppressive, but exactly how this is coordinated and maintained remains poorly understood. We show that multiple transplantable and autochthonous mouse tumors actively elicit a population of highly suppressive regulatory $\mathrm{T}$ cells (Tregs) expressing the lipid phosphatase PTEN. These PTEN+ Tregs co-expressed PD-1, Foxp3, and high levels of Eos (Ikzf4). PTEN signaling acted to stabilize tumor-associated Tregs, maintaining their suppressor activity and preventing conversion into pro-inflammatory effector cells ("ex-Tregs") in the face of inflammation. Mice with a targeted deletion of PTEN in Tregs (PTEN-Treg-KO mice) were healthy and fertile when young, but gradually developed lupus-like autoimmunity as they aged. Tumors implanted in young, healthy PTEN-Treg-KO mice were unable to create the normal immunosuppressive tumor microenvironment; instead, tumors were constitutively immunogenic, chronically inflamed, and could barely grow. In wildtype mice with large, pre-established tumors, pharmacologic inhibition of PTEN during the period following chemotherapy or adoptive immunotherapy caused a profound reconfiguration of the tumor microenvironment. The normally suppressive intratumoral Tregs became destabilized, and rapidly reprogrammed into pro-inflammatory "ex-Tregs" expressing IL-2, IL-17 and CD40L. The dominant APCs in the tumor changed

${ }^{8}$ Georgia Regents University Cancer Center, Augusta, GA, USA

Full list of author information is available at the end of the article from tolerogenic DCs expressing high levels of PD-L1, and were replaced by inflammatory myeloid DCs expressing high levels of CD86, MHC class II, IL-6 and IL-12. $\mathrm{CD} 8+$ effector $\mathrm{T}$ cells in the tumor, which had previously been unresponsive and PD-1+ (exhausted), became activated and expressed IFN $\gamma$ and GzmB, and mediated tumor regression. Pharmacologic inhibition of PTEN was highly synergistic with conventional chemotherapy, allowing a single modest, normally ineffective dose of chemotherapy to trigger rapid tumor involution. This synergy was strictly immune-mediated, and was lost in the absence of host CD8+ T cells. In mice without tumors, identical PTEN+ Tregs were physiologically elicited by exposure to apoptotic cells; and PTEN-Treg-KO mice rapidly developed lupus-like autoimmunity when repeatedly challenged with apoptotic cells. The induction of PTEN+ Tregs by apoptotic cells was driven by indoleamine 2,3-dioxygenase (IDO) in the host, and was blocked by pharmacologic inhibition of IDO. Taken together, these data identify the PTEN pathway in Tregs as a potent immunosuppressive mechanism in tumors. PTEN+ Tregs controlled the downstream activation of inflammatory DCs and effector CD8+ T cells, and were part of the fundamental mechanism of tolerance to apoptotic cells. The PTEN pathway thus represents a potent, centrally-positioned immunosuppressive mechanism in tumors, which is amenable to pharmacologic inhibition and shows 
synergy with both adoptive immunotherapy and conventional chemotherapy.

\section{Authors' details}

${ }^{1}$ Georgia Regents University, Auqusta, GA, USA. ${ }^{2}$ Memorial Sloan-Kettering Cancer Center, New York, NY, USA. ${ }^{3}$ NewLink Genetics, Inc., Ames, IA, USA. ${ }^{4}$ Harvard Medical School, Boston, MA, USA. ${ }^{5}$ Johns Hopkins University School of Medicine, Baltimore, MD, USA. ${ }^{6} J u n t e n d o$ University School of Medicine, Tokyo, Japan. ${ }^{7}$ University of Minnesota, Minneapolis, MN, USA. ${ }^{8}$ Georgia Regents University Cancer Center, Augusta, GA, USA.

Published: 4 November 2015

doi:10.1186/2051-1426-3-S2-019

Cite this article as: Sharma et al: The PTEN pathway in Tregs functions as a critical driver of the immunosuppressive tumor microenvironment and tolerance to apoptotic cells. Journal for ImmunoTherapy of Cancer 2015 3(Suppl 2):O19.

Submit your next manuscript to BioMed Central and take full advantage of:

- Convenient online submission

- Thorough peer review

- No space constraints or color figure charges

- Immediate publication on acceptance

- Inclusion in PubMed, CAS, Scopus and Google Scholar

- Research which is freely available for redistribution

Submit your manuscript at www.biomedcentral.com/submit 